Article

\title{
Performance Evaluation of MQCL Hard Milling of SKD 11 Tool Steel Using $\mathrm{MoS}_{2}$ Nanofluid
}

\author{
Pham Quang Dong, Tran Minh Duc and Tran The Long *(1) \\ Department of Manufacturing Engineering, Faculty of Mechanical Engineering, Thai Nguyen University of \\ Technology, Thai Nguyen 250000, Vietnam; quangdongctm@tnut.edu.vn (P.Q.D.); \\ minhduc@tnut.edu.vn (T.M.D.) \\ * Correspondence: tranthelong90@gmail.com or tranthelong@tnut.edu.vn; Tel.: +84-985-288-777
}

Received: 20 May 2019; Accepted: 3 June 2019; Published: 5 June 2019

\begin{abstract}
The present work shows an experimental investigation on the effect of minimum quantity cooling lubrication (MQCL) during hard milling of SKD 11 tool steel (52-60HRC). The novelty here lies on the use of MQCL technique, which comprises the cooling strategy based on the principle of Ranque-Hilsch vortex tube and MQL method. Moreover, $\mathrm{MoS}_{2}$ nanoparticles are suspended in MQCL based fluid to improve the lubricating character. The response parameters, including surface roughness, surface microstructure, and surface profile are studied. The obtained results show that MQCL using nanofluid gives out better surface quality compared to dry, MQL, and MQCL with pure fluid. Also, the different concentrations of $\mathrm{MoS}_{2}$ nanoparticles are investigated to find out the optimized value as well as the interaction effect on machined surface.
\end{abstract}

Keywords: hard milling; MQCL; emulsion; $\mathrm{MoS}_{2}$ nanoparticles; nanofluid; concentration; surface roughness

\section{Introduction}

Hard cutting processes have been developed along with the growing demand of high productivity, easy adaptation to complex parts, the elimination of cutting fluids, good surface quality, and the reduction of manufacturing cost. Especially, for the growing concern with the climate change, they have gained much attention of the researchers and manufacturers around the world for the promising alternative solution for many of traditional finish grinding operations. These processes directly use the geometrically defined cutting edges for machining the workpieces, with the hardness value typically in the range of 45-70 HRC [1]. The selection of the proper cutting inserts always faces the challenge in order to ensure the good tool life and high precision of the machined parts. Furthermore, the thermal shock must be seriously considered to avoid the breakage of the inserts due to the use of cutting fluids. In the earliest type, dry hard machining, one of the environmental friendly processes, had been applied, gave out the obvious cost benefits, and contributed to overcome the climate change. However, the high-grade inserts, such as coated cemented carbide, ceramics, (P)CBN (Polycrystalline Cubic Boron Nitride), PCD (Cubic Boron Nitride) tools are always demanded for dry cutting due to the high hardness materials and the enormous amount of generated heat [2-7]. There have been many studies for developing the coating layers of carbide tools in order to reduce the contact length at tool chip interface at rake face [2-6]. The obtained results reveal the improvement of hard cutting performance with the reduction of friction coefficient, cutting forces, cutting temperature, and tool wear. On the other hand, the very high cutting temperature was noted during hard machining process [6], which would lead to thermal failure and the reduction of tool life of cutting inserts. In addition to that, the problems caused by thermal distortion of machined parts, handling, and testing process are necessarily considered. Thus, minimum quantity lubrication (MQL) has been developed and widely 
used to overcome the drawbacks of flood and dry machining. The high effectiveness of lubricating is achieved by the use of small amount of cutting fluid with oil mist form that is directly sprayed to contact zone, which leads to the decrease of friction coefficient, cutting forces, cutting temperature, and tool wear, as well as the improvement of surface quality and tool life [8-13]. Davim et al. [14-17] studied the effect of MQL during turning and drilling process and made the comparison to dry and flood conditions. From the obtained results, cutting power, specific cutting forces, and surface quality in both conditions were similar, but were better than those under dry cutting. Furthermore, the authors pointed out that, the lower the vibrations, the higher the surface roughness under MQL condition, while the opposite occurs when dry condition was used [18]. Accordingly, the dry and flood conditions can be successfully replaced by MQL to reduce the negative effects on environment and human health, which will be a step toward sustainable machining [19-21]. The limitation of the cooling effect makes MQL technology difficult to use for hard cutting processes and difficult-to-cut materials. Besides, the use of vegetable oils in order to retain the environmental friendly character of MQL technique faces the difficulty because of the low ignition temperature [22,23]. To develop MQL technique assisted for hard cutting, the new approaches including MQL using nanofluids and MQCL have been studied and prove the promising results.

The application of MQL using different types of nanofluids for difficult-to-cut materials has been an up-to-date research topic in recent years. The MQL base fluids enriched by nanoparticles, such as $\mathrm{Al}_{2} \mathrm{O}_{3}$, $\mathrm{MoS}_{2}, \mathrm{SiO}_{2}, \mathrm{ZrO}_{2}, \mathrm{CNT}, \mathrm{PCD}$, and so on, are proven to possess the enhancement of the tribological property and viscosity, which lead to improve the cutting performance significantly. Li et al. [24] studied the heat transfer performance of MQL grinding while using different nanofluids $\left(\mathrm{MoS}_{2}, \mathrm{ZrO}_{2}\right.$, $\mathrm{CNT}, \mathrm{PCD}, \mathrm{Al}_{2} \mathrm{O}_{3}, \mathrm{SiO}_{2}$ ) for Ni-based alloy. From the obtained results, the improvement of the viscosity and thermal conductivity of base fluids enriched by nanoparticles was observed. From that, the use of nanofluids contributed to reduce the cutting forces and cutting temperature during grinding process. Among these, CNT (Carbon nanotubes) nanofluid has the highest heat transfer coefficient. Lee et al. [25] studied MQL micro grinding using diamond and $\mathrm{Al}_{2} \mathrm{O}_{3}$ nanofluids. Based on the experimental results, it clearly revealed that the grinding forces much reduced and the surface quality was significantly improved. The higher nanofluid concentration and smaller size of nanoparticle were more effective for decreasing the cutting forces. Ali et al. [26] investigated the tribological characteristics of $\mathrm{Al}_{2} \mathrm{O}_{3}$ and $\mathrm{TiO}_{2}$ nano-lubricant in automotive engines with different concentrations $(0.05,0.1,0.25$, and $0.5 \mathrm{wt} \%)$. The results revealed the reduction of friction coefficient, power consumption, and wear. The kinematic viscosity of nano-lubricants decreased slightly, but the viscosity index increased. The most outstanding contribution of this study is that the formation of self-laminating protective films of $\mathrm{Al}_{2} \mathrm{O}_{3}$ nanoparticles made the worn surfaces smoother. The rolling effect created by nanoparticles was important to reduce the friction coefficient. Pashmforoush et al. [27] studied the influence of water-based copper nanofluid on the grinding of the Inconel 738 super alloy. The experimental results indicated the improvement of wheel loading and surface roughness were about $59.19 \%$ and $62.16 \%$ as compared to dry grinding, and $35.13 \%$ and $36.36 \%$ compared to conventional fluid grinding, respectively. Uysal et al. [28] evaluated the MQL milling performance of AISI 420 stainless steel using $\mathrm{MoS}_{2}$ nanofluid. The obtained results also revealed the better lubricating effect of $\mathrm{MoS}_{2}$ nanofluid, which led to the reduction in both tool wear and surface roughness. Zhang et al. [29] investigated the effect of nanoparticle concentration of $\mathrm{MoS}_{2}$ and (carbon nanotubes) CNTs nanofluids for MQL grinding of Ni-based alloy. The results indicated that the use of hybrid $\mathrm{MoS}_{2}$-CNTs nanofluids gave out better surface quality than that of $\mathrm{MoS}_{2}$ and CNTs nanofluids due to the lubrication effect and micromachining of nanoparticles. The nanoparticle concentration had a strong effect on surface quality, so it needed to optimize. Yildırım et al. [30] newly studied MQL turning of Ni-based Inconel 625 using hBN (hexagonal boron nitride) nanofluid. From the results, the authors indicated the significant improvement of tool life and surface quality by using $\mathrm{hBN}$ nanofluid $(0.5 \mathrm{wt} \%)$. They also showed that the cutting temperature and wear rate reduced by using MQL nanofluids when compared to dry machining. Garg et al. [31] studied the effect of nanofluid concentration of MQL micro-drilling process. Based on the obtained results, 
the authors showed that the nanofluid concentration had the strongest influence on the torque and power consumption. Lee et al. [32] studied the stable dispersion of diamond nanoparticles in oil-based fluid and their tribological properties as lubricant additives. The authors concluded that the diamond nanofluid $(0.05 \mathrm{wt} \%)$ reduced the friction coefficient by $23 \%$ and provided the excellent anti-wear properties. The diamond nanoparticles exhibit the great potential application as a new lubricant possessing the excellent tribological performance. Wang et al. [33] conducted the experiments for evaluating the lubrication properties of different nanofluids in MQL grinding. Among the investigated fluids, the authors found that $\mathrm{Al}_{2} \mathrm{O}_{3}$ nanofluid exhibited the good lubrication performance due to characteristics of high hardness and nearly spherical morphology. Luo et al. [34] also indicated that this type of nanofluid demonstrated good resistance to high temperature.

Recently, minimum quantity cooling lubrication (MQCL) has been considered the new solution to overcome the low cooling effect of MQL technique, which can bring out new alternative approaches for machining difficult-to-cut materials and enlarge the MQL applicability. Pervaiz et al. [35] investigated the influence of MQCL in turning Ti6Al4V. The results indicated that the values of surface roughness, cutting forces, and tool wear reduced due to the better cooling and lubricating effect when compared to dry and flood cutting. Maruda and his co-authors [36,37] studied MQCL parameters for hard turning AISI 1045 steel. The authors concluded that the formation of emulsion mist by using MQCL plays an important role in enhancing the cooling lubrication in cutting zone, which contributes to improve the machining performance. The smaller droplet diameters tend to form the lubricating films and penetrate into the contact zone. The authors made the study of the influence extreme pressure and anti-wear (EP/AW) additives on surface topographies during MQCL turning. The formation of tribofilm on the tool-chip interface contributed to reduce the friction and tool wear [38]. They also analyzed the chip formation zone in turning of austenitic stainless steel 316L under MQCL condition [39]. The favorable chip shape has been obtained and the values of the chip thickening coefficient reduced under MQCL condition, which prove the better cooling and lubricating performance. Furthermore, the obtained results indicated that the surface quality and surface topography improved when compared to dry machining. The main reason is that the formation of emulsion mist causes larger amounts of heat to discharge, from which the deformation of the machined surface reduced [40]. The droplet diameter is strongly affected by the distance of the nozzle, and the diameter and number of droplets can be controlled by the volumetric air flow and the nozzle distance from cutting zone. The most outstanding results are the possibility to choose the condition for mist generation, in which all droplets falling on the heated surface within 1 second are evaporated from this surface [41].

However, almost all the studies of MQCL application used the base fluid having the cooling and lubricating property like emulsion. On the other hand, the use of nanoparticle additive to the MQCL base fluid is a new topic and needs to study. Gutnichenko et al. [42] studied the influence of graphite nano additives to vegetable-based oil for MQCL assisted hard turning. The results indicated that the cutting performance significantly improved due to the effect of graphite nanoparticles in reducing the friction in combination with cooling characteristic of MQCL method. The cooling technique assisted cutting processes has been studied in recent years. Sartori et al. [43] investigated the temperature effects when using cooled gaseous nitrogen in semi finishing turning of Ti6Al4V. The authors pointed out that the significant reduction of rake and flank wear, as well as the improvement of surface integrity, was observed by using $\mathrm{N}_{2}$ cooled at $-150{ }^{\circ} \mathrm{C}$. They also investigated the solid lubricant (SL) assisted MQC and MQL techniques for turning [44]. The SL-assisted MQC gave out the lowest wear and best surface quality when compared to dry, conventional wet, and pure MQL technique. Busch et al. [45] studied the effects of $\mathrm{CO}_{2}$ and $\mathrm{N}_{2}$ cooling strategies for turning process of difficult-to-cut materials. The extension of energy efficiency and enhancement of surface integrity were reported. Pereira et al. [46] used the hybrid $\mathrm{CO}_{2}$ and $\mathrm{MQL}$ in milling Inconel 718. The experimental results revealed better cutting performance due to the superior cooling and lubricating compared to wet machining. Bagherzadeh et al. [47] studied the effectiveness of cryogenic $\mathrm{CO}_{2}$ cooling and $\mathrm{MQL}$ for high-speed turning of difficult-to-cut materials. The results indicated that tool wear decreased, tool life increased, and 
surface quality improved. Similar observations were reported when using liquid nitrogen and $\mathrm{CO}_{2}$ cooling [48-50].

From the literature review, it is well documented that almost all the studies used $\mathrm{CO}_{2}$ or nitrogen for cooling, but the use of the principle of Ranque-Hilsch vortex tube [51], a mechanical device that separates a compressed gas into hot and cold streams from ordinary air, in combination with MQL method to form MQCL, is not reported. Hence, the authors are motivated to conduct MQCL hard milling experiments of SKD 11 tool steels (52-60 HRC). Moreover, the study also investigates the effects of $\mathrm{MoS}_{2}$ nanofluid as the MQCL fluid on hard machining performance.

\section{Material and Methods}

\subsection{Experimental Set Up}

The experimental set up is shown in Figure 1. Mazak vertical center smart 530C was used to conduct the experiments. The APMT 1604 PDTR LT30 PVD submicron carbide inserts (made by LAMINA TECHNOLOGIES SA, Yverdon-les-Bains, Switzerland) with flank angle of $11^{\circ}$, nose radius of $0.66 \mathrm{~mm}$, and TiAlN coating layer was utilized. Tool holder type with the designation SHIJIE BAP 400R-50-22-4T with the diameter of $50 \mathrm{~mm}$ was used.

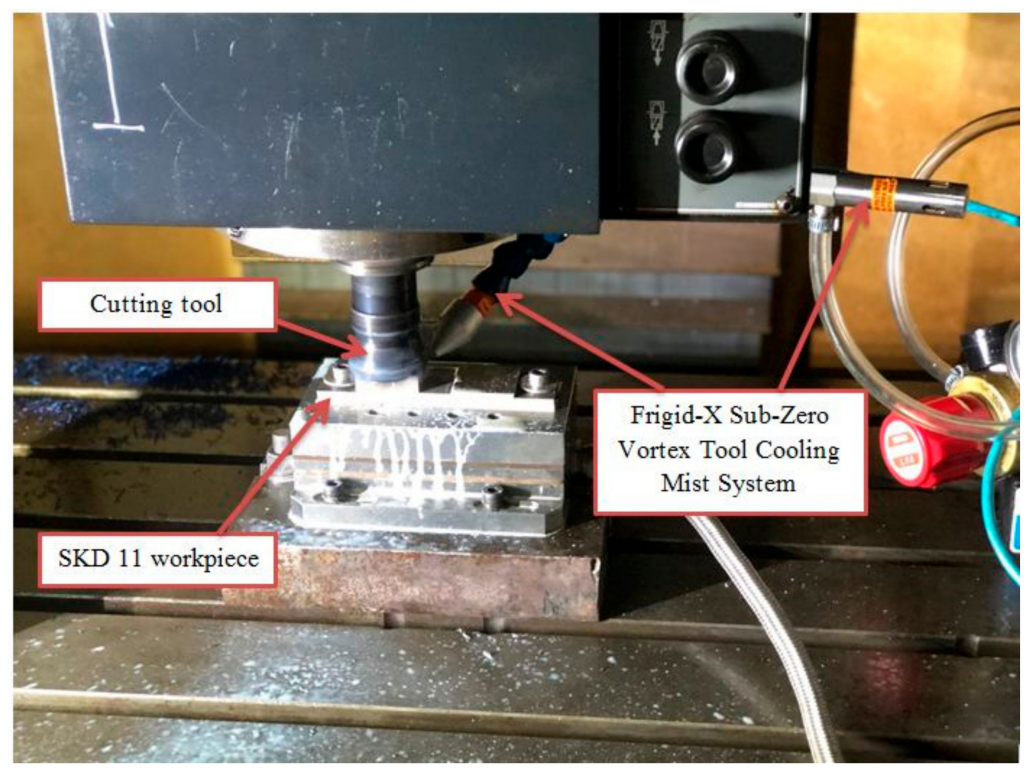

Figure 1. The experimental set up.

The MQCL system includes Frigid-X Sub-Zero Vortex Tool Cooling Mist System (made by Nex Flow $^{\mathrm{TM}}$, Richmond Hill, ON, Canada), compressed air, pressure stabilization device, water-based emulsion 5\%, and $\mathrm{MoS}_{2}$ nanoparticles. Measuring equipment consists of SJ-210 Mitutoyo (Mitutoyo Corporation, Kawasaki, Kanagawa, Japan) for surface roughness. $\mathrm{MoS}_{2}$ nanoparticles made by Luoyang Tongrun Info Technology Co., Ltd. (Luoyang, China) with the size of $30 \mathrm{~nm}$ (average) were used (Figure 2). KEYENCE VHX-6000 Digital Microscope (KEYENCE Corporation, Osaka, Japan) is used to study the surface topography. In this research, the SKD 11 tool steels with the dimensions of $90 \mathrm{~mm} \times 48 \mathrm{~mm} \times 50 \mathrm{~mm}$ and the hardness of 52-60 HRC were used. The chemical composition is shown in Table 1. 


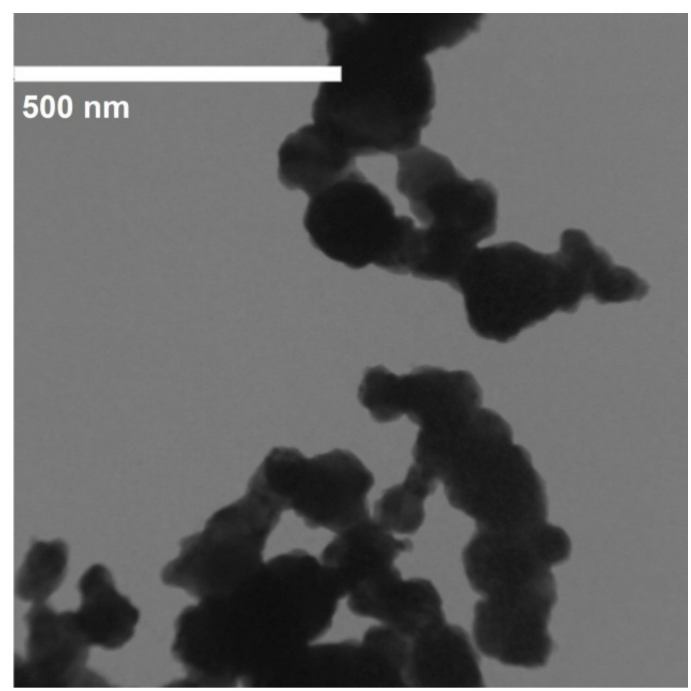

Figure 2. TEM image of $\mathrm{MoS}_{2}$ nanoparticles [52].

Table 1. Chemical composition of SKD 11 steel (According to JIS G4404:1983).

\begin{tabular}{ccccccccccc}
\hline \multicolumn{10}{c}{ Chemical Composition (\%) } \\
\hline $\mathbf{C}$ & $\mathbf{S i}$ & Mn & Ni & Cr & Mo & W & V & Cu & P & S \\
\hline $1.4-1.6$ & 0.4 & 0.6 & 0.5 & $11.0-13.0$ & $0.8-1.2$ & $0.2-0.5$ & $\leq 0.25$ & $\leq 0.25$ & $\leq 0.03$ & $\leq 0.03$ \\
\hline
\end{tabular}

\subsection{The Preparation of $\mathrm{MoS}_{2}$ Nanofluid}

The non-uniform distribution of the nanoparticles in the based fluids will lead to failure in the use of nanofluid [23] and cause the waste. To ensure the uniform suspension of $\mathrm{MoS}_{2}$ nanoparticles in emulsion-based fluids, the prepared nanofluids are kept in Ultrasons-HD ultrasonicator (JP SELECTA, Abrera, Spain), generating $600 \mathrm{~W}$ ultrasonic pulses at $40 \mathrm{kHz}$ for 6 hours. In order to use the obtained nanofluids and avoid the precipitation of agglomerated nanoparticles during the long time of machining, the nanofluid was placed in the 3000868-Ultrasons-HD and directly used for MQCL system.

\subsection{Experiment Design}

Minitab 18.0 software (Minitab Inc., State College, PA, USA) is applied for the Box-Behnken experimental design with three control parameters and their values on three levels are listed in Table 2. Table A1 summarizes the design of experiment with test run order and output in term of surface roughness. The fixed parameters are the feed rate of $0.012 \mathrm{~mm} /$ tooth, depth of cut of $0.12 \mathrm{~mm}$, air pressure of $6 \mathrm{Bar}$, flow rate of $30 \mathrm{~mL} / \mathrm{h}$; the room temperature $24-27^{\circ} \mathrm{C}$; the temperature of output cool air $4-8{ }^{\circ} \mathrm{C}$. The experimental trials are repeated by three times under the same cutting parameters.

Table 2. Control factors and their levels.

\begin{tabular}{cccccc}
\hline \multirow{2}{*}{ Control Factor } & \multirow{2}{*}{ Unit } & \multirow{2}{*}{ Symbol } & \multicolumn{3}{c}{ Level } \\
\cline { 4 - 6 } & & & Low & Medium & High \\
\hline Nanoparticle concentration $(\mathrm{np})$ & $\mathrm{wt} \%$ & $x_{1}$ & 0.5 & 1.0 & 1.5 \\
\hline Cutting speed $(V c)$ & $\mathrm{m} / \mathrm{min}$ & $x_{2}$ & 90 & 100 & 110 \\
\hline Hardness & $\mathrm{HRC}$ & $x_{3}$ & 52 & 56 & 60 \\
\hline
\end{tabular}




\section{Results and Discussion}

\subsection{The Effects of Input Machining Parameters on Surface Roughness}

The ANOVA analysis is carried out at a confidence level of 95\% (i.e., 5\% significance level). Table A2 shows the results of ANOVA analysis. The regression model of surface roughness $R_{a}$ is given below in Equation (1).

$$
R_{a}=6.54+0.2521 \cdot x_{1}+0.0051 \cdot x_{2}-0.2387 \cdot x_{3}-0.1131 \cdot x_{1} \cdot x_{1}-0.000028 \cdot x_{2} \cdot x_{2}+0.002109 \cdot x_{3} \cdot x_{3}
$$

The Pareto chart of the standardized effects with $\alpha=0.05$ for the response parameter $R_{a}$ is shown in Figure 3. The nanoparticle concentration $\left(x_{1}\right)$ has a strongest influence, followed by the hardness $\left(x_{3}\right)$ and cutting speed $\left(x_{2}\right)$. The effects of these input machining parameters are also reflected by the corresponding coefficients in Equation (1). The interaction effects CC $\left(x_{3} x_{3}\right)$, AA $\left(x_{1} x_{1}\right)$ reveal the significant influence on the investigated function, which is contrary to BB $\left(x_{2} x_{2}\right)$. The other interaction effects of $x_{1} x_{2}, x_{1} x_{3}, x_{2} x_{3}$ have a very little influence and are not investigated in the model. From the analysis of the effects of three input machining parameters, the proper selection of nanoparticle concentration and the material hardness need to study in order to improve the surface roughness.

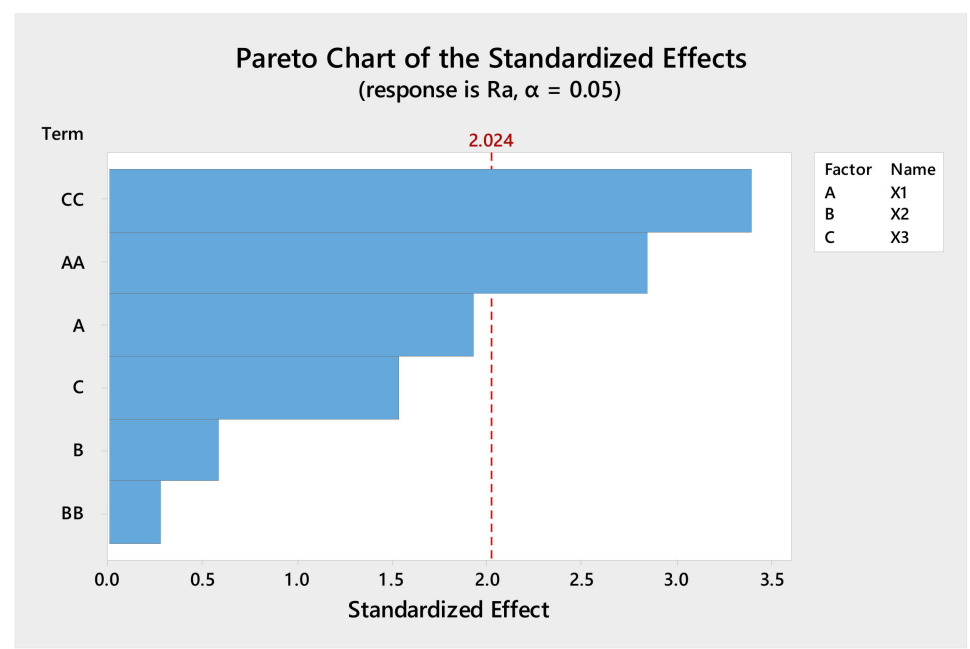

Figure 3. Pareto chart of the effects of investigated parameters on surface roughness $R_{a}$.

From the surface plot (Figure 4a) and contour plot (Figure $4 \mathrm{~b}$ ), the effects of the nanoparticle concentration and cutting speed on the value of surface roughness $R_{a}$ indicate that the optimized value $R_{a}$ is about $0.11 \mu \mathrm{m}$, with $\mathrm{np}=0.5 \mathrm{wt} \%$ and $V_{c}=93-110 \mathrm{~m} / \mathrm{min}$.

From the surface plot (Figure 5a) and contour plot (Figure 5b), the effects of nanoparticle concentration $\left(x_{1}\right)$ and hardness $\left(x_{3}\right)$ on surface roughness $R_{a}$ indicate that the optimized value $R_{a}$ is about $0.12 \mu \mathrm{m}$, with $x_{1}=0.5 \mathrm{wt} \%$ and $x_{3}=55-58 \mathrm{HRC}$.

From the surface plot (Figure 6a) and contour plot (Figure 6b), the effects of cutting speed $\left(x_{2}\right)$ and hardness $\left(x_{3}\right)$ on surface roughness $R_{a}$ indicate that the optimized value $R_{a}$ is about $0.15 \mu \mathrm{m}$, with $x_{2}=95-110 \mathrm{~m} / \mathrm{min}$. and $x_{3}=55-58 \mathrm{HRC}$.

The prediction of the optimized value of surface roughness $R_{a}$ is $0.1070 \mu \mathrm{m}$ (Figure 7), with $x_{1}=0.5 \mathrm{wt} \% ; x_{2}=110 \mathrm{~m} / \mathrm{min} ; x_{3}=56.6061 \mathrm{HRC}$. In Figure 5, it can be clearly seen that the Figure 5 . The effects of nano concentration and hardness on surface roughness $R_{a}$. graph of surface roughness does not show the extreme point with nanoparticle concentration of $0.5 \mathrm{wt} \%$. Therefore, the following investigation is done to find the optimal value. 


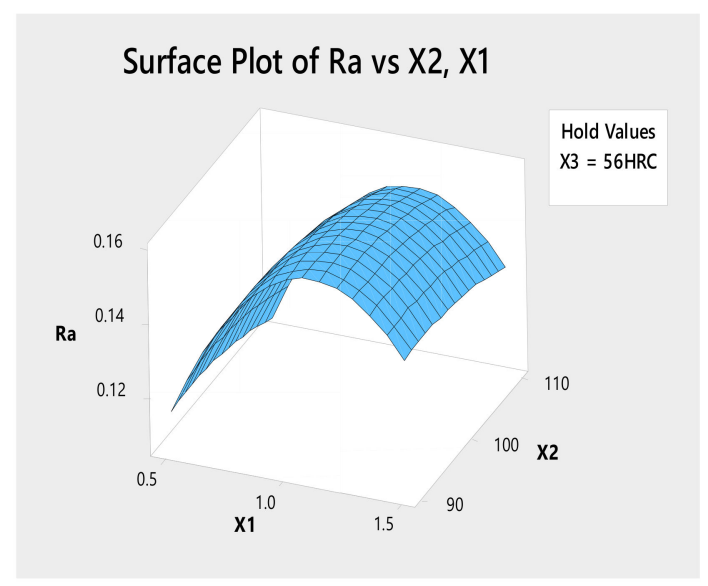

(a)

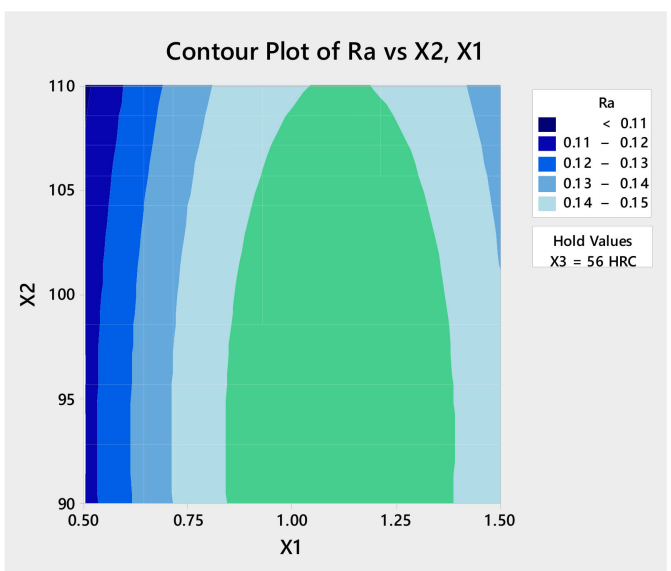

(b)

Figure 4. The effects of nano concentration and cutting speed on surface roughness $R_{a}$. (a) Surface plot of $R_{a}$ versus cutting speed and nano concentration; (b) Contour plot of $R_{a}$ versus cutting speed and nano concentration.

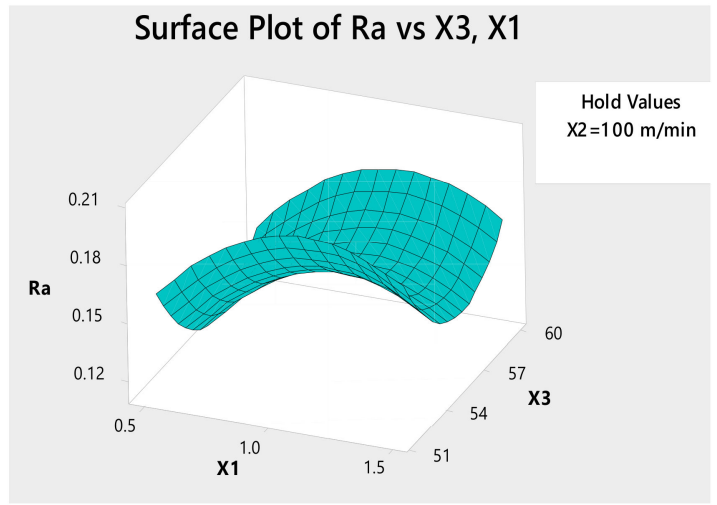

(a)

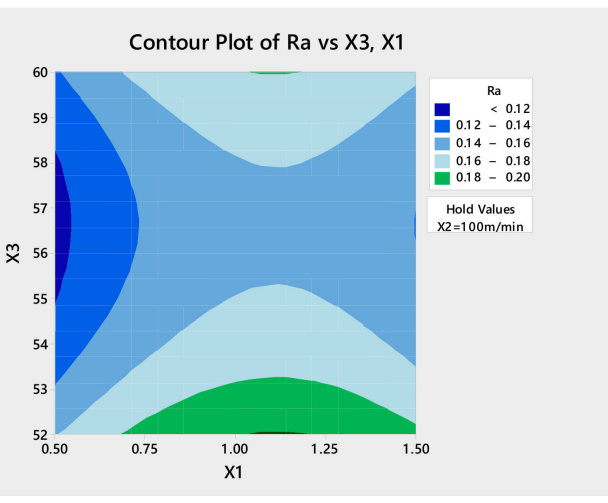

(b)

Figure 5. The effects of nano concentration and hardness on surface roughness $R_{a}$.

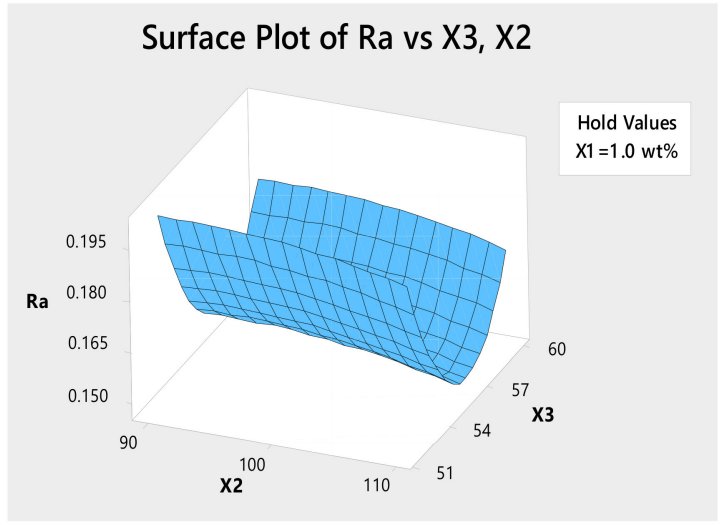

(a)

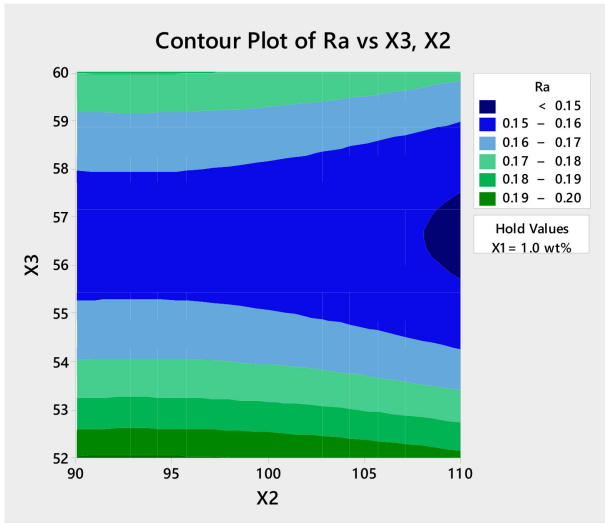

(b)

Figure 6. The effects of cutting speed and hardness on surface roughness $R_{a}$. 


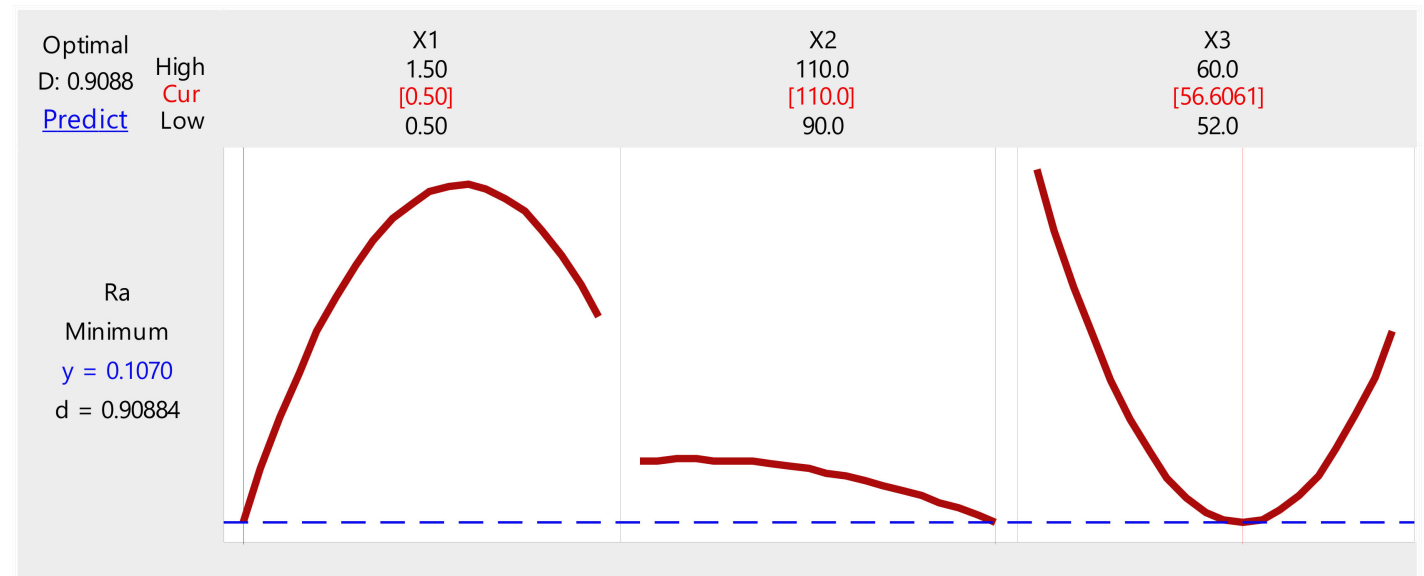

Figure 7. The optimized graphs for surface roughness $R_{a}$.

\subsection{The Optimized and Validated Experiments}

The experiments aim to compare the effects of dry, MQL pure emulsion-based fluid, MQCL pure emulsion-based fluid, and MQCL emulsion-based nanofluid, from which the effectiveness of MQCL emulsion-based nanofluid can be evaluated more accurately in hard machining. Moreover, the experimental study is made to find the optimized concentration of $\mathrm{MoS}_{2}$ nanoparticles based on the obtained parameters in Figure 7 (cutting speed of $110 \mathrm{~m} / \mathrm{min}$., hardness of 56 HRC). Three different $\mathrm{MoS}_{2}$ nanoparticles concentrations of $0.2 \mathrm{wt} \%, 0.5 \mathrm{wt} \%$, and $0.8 \mathrm{wt} \%$ are used in the experiments. The average values of surface roughness $R_{a}$ and microstructure and profiles of machined surface under different conditions are given by Figures 8-13.

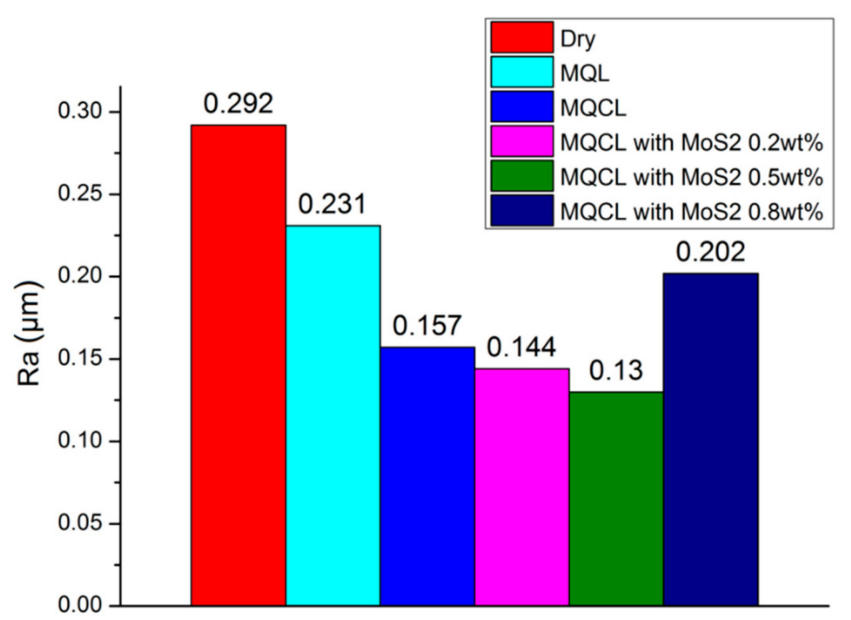

Figure 8. The average values of surface roughness $R_{a}$ under different conditions. 


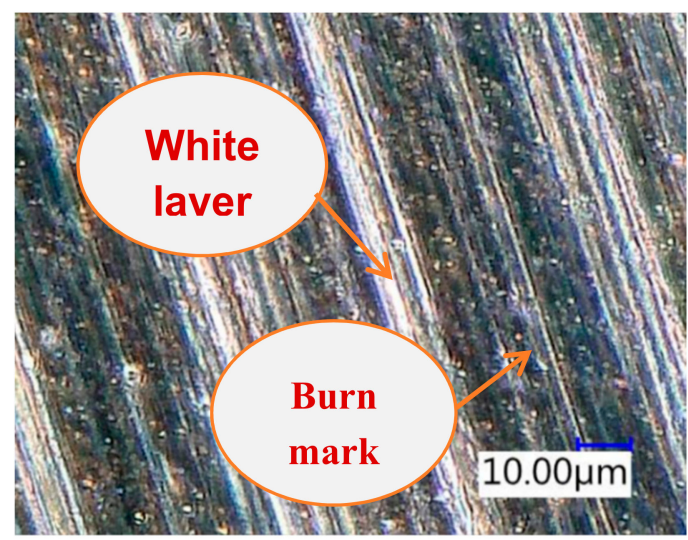

(a)

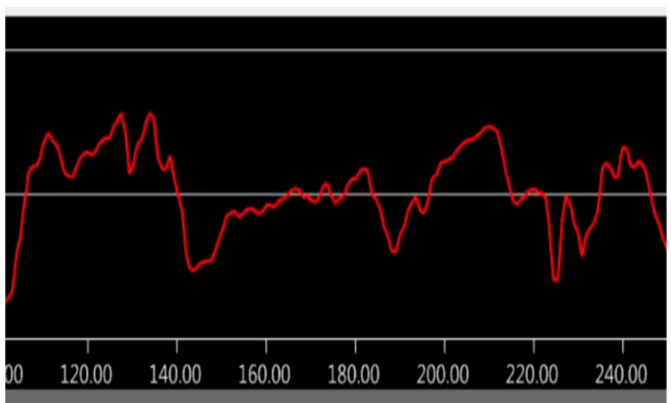

(b)

Figure 9. Microstructure (a) and profile (b) of machined surface under dry condition.

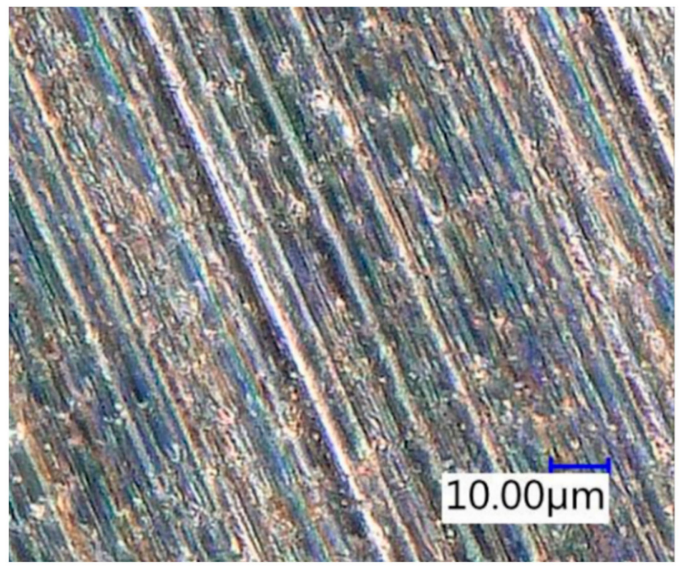

(a)

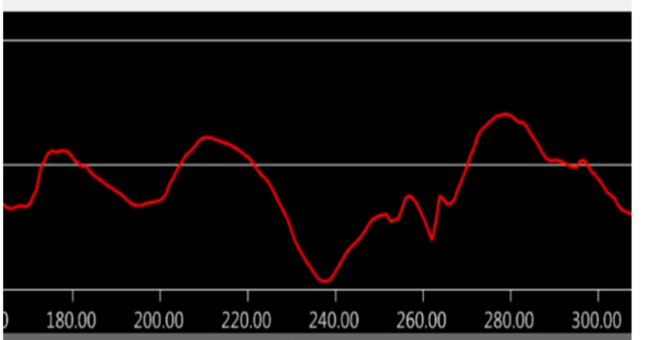

(b)

Figure 10. Microstructure (a) and profile (b) of machined surface under MQL condition.

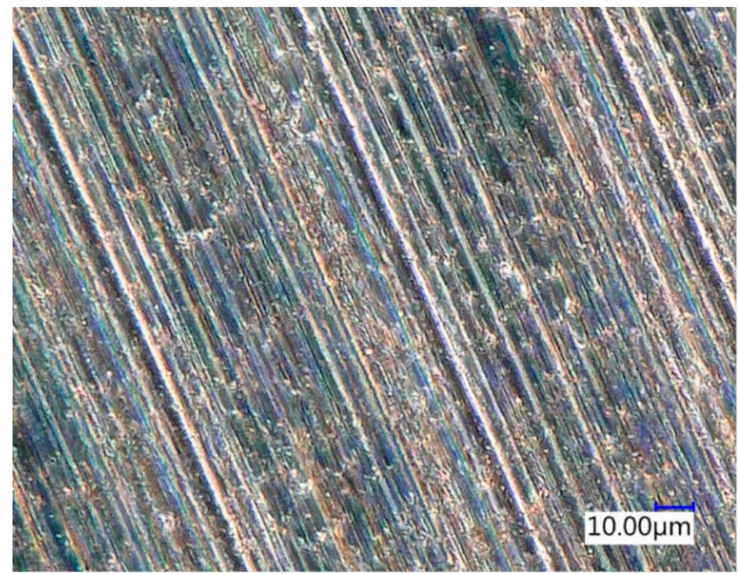

(a)

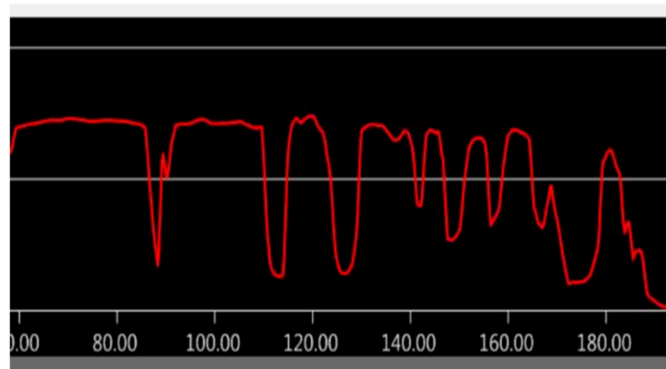

(b)

Figure 11. Microstructure (a) and profile (b) of machined surface under MQCL condition with pure emulsion-based fluid. 


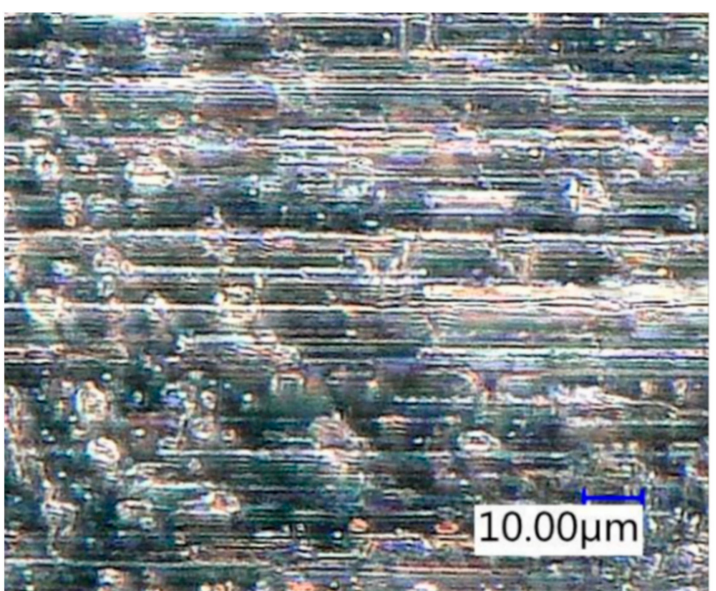

(a)

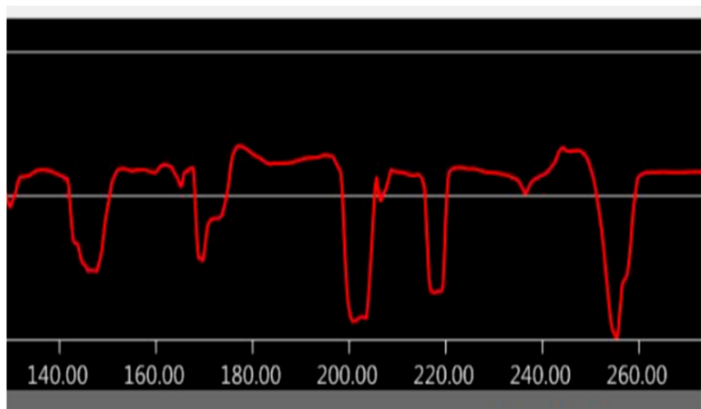

(b)

Figure 12. Microstructure (a) and profile (b) of machined surface under MQCL condition with emulsion-based nanofluid of $\mathrm{MoS}_{2} 0.2 \mathrm{wt} \%$.

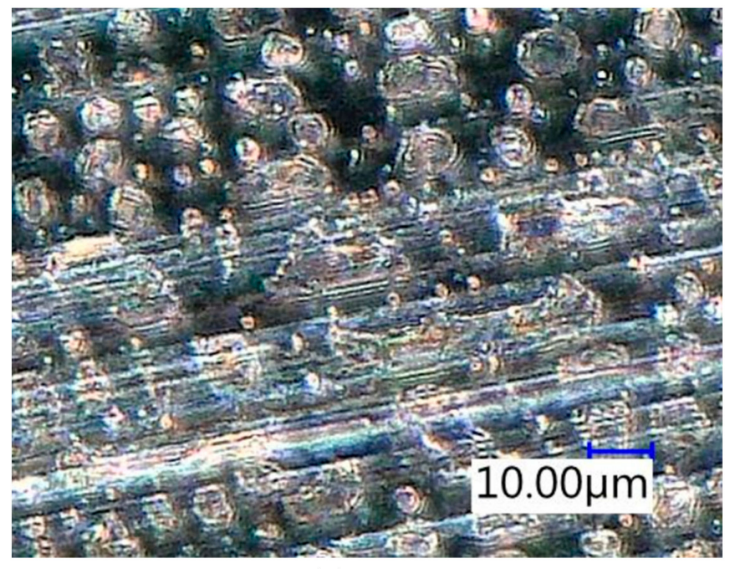

(a)

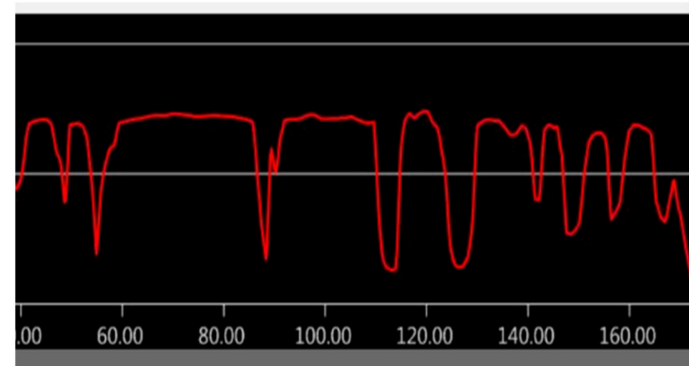

(b)

Figure 13. Microstructure (a) and profile (b) of machined surface under MQCL condition with emulsion-based nanofluid of $\mathrm{MoS}_{2} 0.5 \mathrm{wt} \%$.

\subsubsection{The Effects of Cooling and Lubricating on Surface Quality}

From Figure 8, the average value of surface roughness $R_{a}$ under dry cutting is largest $\left(R_{a}=0.292\right.$ $\mu \mathrm{m})$ followed by MQL with pure emulsion-based fluid $\left(R_{a}=0.231 \mu \mathrm{m}\right.$; the reduction of about $\left.20.9 \%\right)$ and MQCL with pure emulsion-based fluid $\left(R_{a}=0.157 \mu \mathrm{m}\right.$; the reduction of about $\left.33.1 \%\right)$. MQCL with $\mathrm{MoS}_{2}$ emulsion-based nanofluids shows the better surface roughness, especially with the concentration of $0.2 \mathrm{wt} \%\left(R_{a}=0.144 \mu \mathrm{m}\right)$ and $0.5 \mathrm{wt} \%\left(R_{a}=0.130 \mu \mathrm{m}\right)$. Interestingly, the value of surface roughness increases from $0.130 \mu \mathrm{m}$ to $0.202 \mu \mathrm{m}$ when the nanoparticle concentration rises from 0.5 to $0.8 \mathrm{wt} \%$, which is similar to the study of $\mathrm{MoS}_{2}$ nanofluid in $[52,53]$. Studying the microstructure and profile of machined surface in Figures 9-13, the white-layer and burn marks under MQL condition are reduced when compared with dry cutting. The compression phenomena of machined surface under MQL condition is significantly decreased by observing the surface profile. The main reason is that MQL technique with emulsion-based fluid provided the better lubricating condition in the cutting zone. Compared to MQL condition, the surface microstructure under MQCL with pure emulsion-based fluid significantly improves and the surface profile is smoother (Figures 10 and 11). The white-layer and burn marks much reduced due to the better cooling performance. In case of using MQCL with $\mathrm{MoS}_{2}$ emulsion-based nanofluids, the surface microstructure and profile are similar to those of MQCL with pure fluid, but the value of surface roughness is slightly better (Figures 11-13). $\mathrm{MoS}_{2}$ nanoparticles are ellipsoidal and they provide the low coefficient of friction up to $0.03-0.05$ or even lower caused by 
the weak binding of sulfur atoms between molecular layers to create "an easy-to-slide plane" [23], by which it proves the better lubricating performance of $\mathrm{MoS}_{2}$ nanoparticles in MQCL technique.

\subsubsection{The Effect of $\mathrm{MoS}_{2}$ Nanoparticle Concentration on Surface Roughness}

The effects of $\mathrm{MoS}_{2}$ nanoparticle concentration on the value of surface roughness (Figure 8) indicate that the average values of surface roughness are $0.144,0.130$, and $0.202 \mu \mathrm{m}$, corresponding to the nano concentration of $0.2,0.5$, and $0.8 \mathrm{wt} \%$. Accordingly, the optimized surface roughness occurs in the concentration range of $0.2-0.8 \mathrm{wt} \%$, so $\mathrm{MoS}_{2}$ nanoparticle concentration of about $0.5 \mathrm{wt} \%$ can be suggested to use in this case.

The microstructure and profiles of machined surface captured by KEYENCE VHX-6000 Digital Microscope are investigated in Figures 9-13 and reveal that $\mathrm{MoS}_{2}$ nanoparticle concentration has a strong effect. The novel observation is that the so-called "micro bubbles" remain on the machined surface, which increase with the rise of nanoparticle concentration shown in Figures 12 and 13 . The morphology of $\mathrm{MoS}_{2}$ nanoparticles is ellipsoidal and they possess the large surface area; therefore, they remain on the machined surface and form a thin protective film, which amplifies when the nanoparticle concentration increases [53] and contributes to form the tribofilm easily [38]. In addition, the oil mist containing $\mathrm{MoS}_{2}$ nanoparticles plays an important role in improving the cooling and lubricating characteristics in cutting zone $[29,54-56]$. However, when the concentration of $\mathrm{MoS}_{2}$ nanoparticles in emulsion-based fluid rises to $0.8 \mathrm{wt} \%$, it causes a negative effect on surface roughness [53]. Accordingly, the proper concentration in this case is $0.5 \mathrm{wt} \%$, but more investigations need to study and explain this observation.

\subsubsection{The Effect of MQCL Technique Using $\mathrm{MoS}_{2}$ Nanofluid on Cutting Performance}

The cutting performance of normal carbide tools is significantly improved in hard milling due to the better cooling and lubricating effects of MQCL technique. In the previous studies, the cutting speed of carbide inserts increased to $110 \mathrm{~m} / \mathrm{min}$. during MQL milling of hardened steel (50-52HRC), which is 2 times higher than the recommended cutting speed of the manufacturer [22,57]. In this work, the carbide tools still show the effectiveness during cutting the difficult-to-cut steel with the range of hardness of 56-60 HRC, while remaining the cutting speed of $110 \mathrm{~m} / \mathrm{min}$., which is about 2.75 times higher than that of the manufacturer's recommendation. It clearly reveals the superior cooling and lubricating effects on cutting zone by using MQCL method with $\mathrm{MoS}_{2}$ nanofluid. From that, the manufacturing cost significantly reduces and the cutting applicability of carbide tools enlarges.

\section{Conclusions}

ANOVA analysis is applied for the Box-Behnken experimental design to evaluate the effects of variables on the objective functions, from which the directions of further studies can be made. In this study, the influence of MQCL parameters including the nanoparticle concentration, cutting speed, and hardness is investigated in terms of surface roughness. The interaction effects of hardness and nanoparticle concentration reveal the strongest influence on the investigated function.

The MQCL tool named by Frigid-X Sub-Zero Vortex Tool Cooling Mist System based on the principle of Ranque-Hilsch vortex tube in combination with MQL is applied in the hard milling of SKD 11 tool steels (52-60 HRC) using cemented carbide tools. This is the first attempt to investigate the novel MQCL using $\mathrm{MoS}_{2}$ nanofluid. The surface roughness, surface microstructure, and surface profile of machined surface are better under the MQCL technique using $\mathrm{MoS}_{2}$ additives in emulsion-based fluid when compared to dry, MQL pure fluid, and MQCL pure fluid. The enhancement of lubricating characteristic is observed due to the presence of $\mathrm{MoS}_{2}$ nanoparticles, which contribute to form oil mist.

The form of white layers and burn marks are much reduced by using MQCL technique due to the better cooling and lubricating performance, which can overcome the main drawback of MQL method. The application of MQCL technique in hard machining brings out a promising alternative solution 
for dry and wet, MQL conditions, enlarges the cutting applicability of difficult-to-cut materials, and contributes to prevent climate change.

The normal carbide inserts can be effectively used in hard milling under MQCL technique with $\mathrm{MoS}_{2}$ nanofluid, which contributes to enlarge the cutting applicability and decrease the manufacturing cost. Moreover, MQCL tool only needs ordinary air for cooling, which will reduce the expense of using other cooling gases.

The $\mathrm{MoS}_{2}$ nanoparticle concentration in emulsion-based fluid for MQCL technique is investigated and optimized by experiments. The optimized value is $0.5 \mathrm{wt} \%$. When the concentration is larger than $0.5 \mathrm{wt} \%$, the surface roughness becomes worse. The observation will provide the necessary technical guideline on using $\mathrm{MoS}_{2}$ nanofluids and hybrid nanofluid more efficiently.

In further research, more investigations need to be focused on the effects of nanoparticle concentration on surface quality. The influences of other properties like nanoparticle morphology, nanoparticle size are necessary to be studied. In addition, more focus will be given to investigate the impact of feed rate and the parameters of MQCL using nanofluid.

Author Contributions: Conceptualization, P.Q.D., T.M.D and T.T.L.; methodology, P.Q.D. and T.M.D; software, T.M.D. and T.T.L.; validation, P.Q.D., T.M.D. and T.T.L.; formal analysis, T.M.D. and T.T.L.; investigation, P.Q.D.; resources, T.T.L.; data curation, P.Q.D. and T.T.L.; writing-original draft preparation, P.Q.D., T.M.D., and T.T.L.; writing-review and editing, P.Q.D., T.M.D., and T.T.L.; visualization, P.Q.D.; supervision, T.M.D. and T.T.L.; project administration, T.M.D.

Funding: This research was funded by Vietnam Ministry of Education and Training with the project number of B2019-TNA-02.

Acknowledgments: The study had the support of Vietnam Ministry of Education and Training and Thai Nguyen University of Technology, Thai Nguyen University with the project number of B2019-TNA-02.

Conflicts of Interest: The authors declare no conflict of interest.

\section{Appendix A}

Table A1. The design of experiment with test run order and output in term of surface roughness.

\begin{tabular}{cccccccc}
\hline $\begin{array}{c}\mathbf{1} \text { Std } \\
\text { Order }\end{array}$ & $\begin{array}{c}\text { Run } \\
\text { Order }\end{array}$ & $\mathbf{2}$ Pt Type & Blocks & \multicolumn{2}{c}{ Input Machining Parameters } & $\begin{array}{c}\text { Response } \\
\text { Variable }\end{array}$ \\
\cline { 5 - 7 } & & & & $\mathbf{X}_{\mathbf{1}}$ & $\mathbf{X}_{\mathbf{2}}$ & $\mathbf{X}_{\mathbf{3}}$ & $\boldsymbol{R}_{\boldsymbol{a}}$ \\
\hline $\mathbf{1}$ & $\mathbf{2 0}$ & $\mathbf{2}$ & 1 & 0.5 & 90 & 56 & 0.115 \\
2 & 30 & 2 & 1 & 1.5 & 90 & 56 & 0.139 \\
3 & 7 & 2 & 1 & 0.5 & 110 & 56 & 0.127 \\
4 & 41 & 2 & 1 & 1.5 & 110 & 56 & 0.118 \\
5 & 4 & 2 & 1 & 0.5 & 100 & 52 & 0.201 \\
6 & 39 & 2 & 1 & 1.5 & 100 & 52 & 0.257 \\
7 & 32 & 2 & 1 & 0.5 & 100 & 60 & 0.189 \\
8 & 14 & 2 & 1 & 1.5 & 100 & 60 & 0.212 \\
9 & 16 & 2 & 1 & 1 & 90 & 52 & 0.202 \\
10 & 29 & 2 & 1 & 1 & 110 & 52 & 0.161 \\
11 & 22 & 2 & 1 & 1 & 90 & 60 & 0.214 \\
12 & 18 & 2 & 1 & 1 & 110 & 60 & 0.194 \\
13 & 23 & 0 & 1 & 1 & 100 & 56 & 0.116 \\
14 & 43 & 0 & 1 & 1 & 100 & 56 & 0.131 \\
15 & 19 & 0 & 1 & 1 & 100 & 56 & 0.139 \\
16 & 11 & 2 & 1 & 0.5 & 90 & 56 & 0.092 \\
17 & 21 & 2 & 1 & 1.5 & 90 & 56 & 0.179 \\
18 & 13 & 2 & 1 & 0.5 & 110 & 56 & 0.141 \\
19 & 37 & 2 & 1 & 1.5 & 110 & 56 & 0.109 \\
20 & 38 & 2 & 1 & 0.5 & 100 & 52 & 0.112 \\
21 & 33 & 2 & 1 & 1.5 & 100 & 52 & 0.187 \\
\hline
\end{tabular}


Table A1. Cont.

\begin{tabular}{|c|c|c|c|c|c|c|c|}
\hline \multirow{2}{*}{$\begin{array}{l}{ }^{1} \text { Std } \\
\text { Order }\end{array}$} & \multirow{2}{*}{$\begin{array}{l}\text { Run } \\
\text { Order }\end{array}$} & \multirow{2}{*}{${ }^{2}$ Pt Type } & \multirow{2}{*}{ Blocks } & \multicolumn{3}{|c|}{ Input Machining Parameters } & \multirow{2}{*}{$\begin{array}{c}\text { Response } \\
\text { Variable }\end{array}$} \\
\hline & & & & $x_{1}$ & $X_{2}$ & $X_{3}$ & \\
\hline 22 & 12 & 2 & 1 & 0.5 & 100 & 60 & 0.111 \\
\hline 23 & 9 & 2 & 1 & 1.5 & 100 & 60 & 0.124 \\
\hline 24 & 28 & 2 & 1 & 1 & 90 & 52 & 0.189 \\
\hline 25 & 45 & 2 & 1 & 1 & 110 & 52 & 0.207 \\
\hline 26 & 10 & 2 & 1 & 1 & 90 & 60 & 0.196 \\
\hline 27 & 2 & 2 & 1 & 1 & 110 & 60 & 0.184 \\
\hline 28 & 15 & 0 & 1 & 1 & 100 & 56 & 0.151 \\
\hline 29 & 36 & 0 & 1 & 1 & 100 & 56 & 0.138 \\
\hline 30 & 27 & 0 & 1 & 1 & 100 & 56 & 0.229 \\
\hline 31 & 6 & 2 & 1 & 0.5 & 90 & 56 & 0.112 \\
\hline 32 & 17 & 2 & 1 & 1.5 & 90 & 56 & 0.102 \\
\hline 33 & 5 & 2 & 1 & 0.5 & 110 & 56 & 0.101 \\
\hline 34 & 3 & 2 & 1 & 1.5 & 110 & 56 & 0.162 \\
\hline 35 & 35 & 2 & 1 & 0.5 & 100 & 52 & 0.138 \\
\hline 36 & 25 & 2 & 1 & 1.5 & 100 & 52 & 0.165 \\
\hline 37 & 42 & 2 & 1 & 0.5 & 100 & 60 & 0.121 \\
\hline 38 & 1 & 2 & 1 & 1.5 & 100 & 60 & 0.118 \\
\hline 39 & 31 & 2 & 1 & 1 & 90 & 52 & 0.201 \\
\hline 40 & 26 & 2 & 1 & 1 & 110 & 52 & 0.192 \\
\hline 41 & 8 & 2 & 1 & 1 & 90 & 60 & 0.175 \\
\hline 42 & 40 & 2 & 1 & 1 & 110 & 60 & 0.126 \\
\hline 43 & 44 & 0 & 1 & 1 & 100 & 56 & 0.141 \\
\hline 44 & 24 & 0 & 1 & 1 & 100 & 56 & 0.172 \\
\hline 45 & 34 & 0 & 1 & 1 & 100 & 56 & 0.185 \\
\hline
\end{tabular}

${ }^{1}$ Std order means standard order; ${ }^{2}$ Pt Type means Point Type.

Table A2. Results of ANOVA analysis of surface roughness $R_{a}$.

\begin{tabular}{cccccc}
\hline Source & DF & Adj SS & Adj MS & F-Value & $p$-Value \\
\hline Model & 6 & 0.030316 & 0.005053 & 4.63 & $<0.001$ \\
\hline Linear & 3 & 0.006987 & 0.002329 & 2.14 & 0.112 \\
\hline$X_{1}$ & 1 & 0.004056 & 0.004056 & 3.72 & 0.061 \\
\hline$X_{2}$ & 1 & 0.000368 & 0.000368 & 0.34 & 0.565 \\
\hline$X_{3}$ & 1 & 0.002563 & 0.002563 & 2.35 & 0.134 \\
\hline Square & 3 & 0.023329 & 0.007776 & 7.13 & $<0.001$ \\
\hline$X_{1}{ }^{*} X_{1}$ & 1 & 0.008849 & 0.008849 & 8.12 & $<0.007$ \\
\hline$X_{2}{ }^{*} X_{2}$ & 1 & 0.000085 & 0.000085 & 0.08 & 0.782 \\
\hline$X_{3}{ }^{*} X_{3}$ & 1 & 0.012607 & 0.012607 & 11.56 & $<0.002$ \\
\hline Error & 38 & 0.041433 & 0.001090 & - & - \\
\hline Lack-of-Fit & 6 & 0.003599 & 0.000600 & 0.51 & 0.798 \\
\hline Pure Error & 32 & 0.037834 & 0.001182 & - & - \\
\hline Total & 44 & 0.071750 & - & - & - \\
\hline
\end{tabular}




\section{References}

1. Davim, J.P. Machining of Hard Materials; Springer: London, UK, 2011.

2. Bouacha, K.; Yallese, M.A.; Mabrouki, T.; Rigal, J.-F. Statistical analysis of surface roughness and cutting forces using response surface methodology in hard turning of AISI 52100 bearing steel with CBN tool. Int. J. Refract. Met. Hard Mater. 2010, 28, 349-361. [CrossRef]

3. Zhang, K.; Deng, J.; Meng, R.; Gao, P.; Yue, H. Effect of nano-scale textures on cutting performance of WC/Co-based Ti55Al45N coated tools in dry cutting. Int. J. Refract. Met. Hard Mater. 2015, 51, 35-49. [CrossRef]

4. Liu, Y.; Deng, J.; Wang, W.; Duan, R.; Meng, R.; Ge, D.; Li, X. Effect of texture parameters on cutting performance of flank-faced textured carbide tools in dry cutting of green $\mathrm{Al}_{2} \mathrm{O}_{3}$ ceramics. Ceram. Int. 2018, 44, 13205-13217. [CrossRef]

5. Kumar, C.S.; Patel, S.K. Effect of WEDM surface texturing on $\mathrm{Al}_{2} \mathrm{O}_{3} / \mathrm{TiCN}$ composite ceramic tools in dry cutting of hardened steel. Ceram. Int. 2018, 44, 2510-2523. [CrossRef]

6. Xing, Y.; Deng, J.; Zhao, J.; Zhang, G.; Zhang, K. Cutting performance and wear mechanism of nanoscale and microscale textured $\mathrm{Al}_{2} \mathrm{O}_{3} / \mathrm{TiC}$ ceramic tools in dry cutting of hardened steel. Int. J. Refract. Met. Hard Mater. 2014, 43, 46-58. [CrossRef]

7. Su, Y.; Li, Z.; Li, L.; Wang, J.; Gao, H.; Wang, G. Cutting performance of micro-textured polycrystalline diamond tool in dry cutting. J. Manuf. Process. 2017, 27, 1-7. [CrossRef]

8. Rahim, E.A.; Dorairaju, H. Evaluation of mist flow characteristic and performance in Minimum Quantity Lubrication (MQL) machining. Measurement 2018, 123, 213-225. [CrossRef]

9. Abdul Sani, A.S.; Rahim, E.A.; Sharif, S.; Sasahara, H. Machining performance of vegetable oil with phosphonium- and ammonium-based ionic liquids via MQL technique. J. Clean. Prod. 2019, 209, 947-964. [CrossRef]

10. Joshi, K.K.; Kumar, R.; Anurag. An Experimental Investigations in Turning of Incoloy 800 in Dry, MQL and Flood Cooling Conditions. Procedia Manuf. 2018, 20, 350-357. [CrossRef]

11. Tunc, L.T.; Gu, Y.; Burke, M.G. Effects of Minimal Quantity Lubrication (MQL) on Surface Integrity in Robotic Milling of Austenitic Stainless Steel. Procedia CIRP 2016, 45, 215-218. [CrossRef]

12. Duc, T.M.; Long, T.T. Investigation of MQL-Employed Hard-Milling Process of S60C Steel Using Coated-Cemented Carbide Tools. J. Mech. Eng. Autom. 2016, 6, 128-132.

13. Kang, M.; Kim, K.; Shin, S.; Jang, S.; Park, J.; Kim, C. Effect of the minimum quantity lubrication in high-speed end-milling of AISI D2 cold-worked die steel (62 HRC) by coated carbide tools. Surf. Coat. Technol. 2008, 202, 5621-5624. [CrossRef]

14. Davim, J.P.; Sreejith, P.S.; Silva, J. Turning of Brasses Using Minimum Quantity of Lubricant (MQL) and Flooded Lubricant Conditions. Mater. Manuf. Process. 2007, 22, 45-50. [CrossRef]

15. Davim, J.P.; Sreejith, P.S.; Gomes, R.; Peixoto, C. Experimental studies on drilling of aluminium (AA1050) under dry, minimum quantity of lubricant, and flood-lubricated conditions. Proc. Inst. Mech. Eng. Part B J. Eng. Manuf. 2006, 220, 1605-1611. [CrossRef]

16. Gaitonde, V.N.; Karnik, S.R.; Davim, J.P.; Gaitonde, V. Optimal MQL and Cutting Conditions Determination for Desired Surface Roughness in Turning of Brass Using Genetic Algorithms. Mach. Sci. Technol. 2012, 16, 304-320. [CrossRef]

17. Carou, D.; Rubio, E.M.; Davim, J.P. A note on the use of the minimum quantity lubrication (MQL) system in turning. Ind. Lubr. Tribol. 2015, 67, 256-261. [CrossRef]

18. Carou, D.; Rubio, E.; Lauro, C.; Davim, J.P.; Porto, D.C.; Lauro, C. The effect of minimum quantity lubrication in the intermittent turning of magnesium based on vibration signals. Measurement 2016, 94, 338-343. [CrossRef]

19. Gupta, K.; Laubscher, R.; Davim, J.P.; Jain, N.K. Recent developments in sustainable manufacturing of gears: A review. J. Clean. Prod. 2016, 112, 3320-3330. [CrossRef]

20. Davim, J.P. (Ed.) Sustainable Manufacturing; ISTE Ltd.: London, UK; John Wiley \& Sons, Inc.: Hoboken, NJ, USA, 2010; ISBN 978-1-84821-212-1.

21. Davim, J.P. (Ed.) Green Manufacturing Processes and Systems; Materials Forming, Machining and Tribology; Springer: Berlin/Heidelberg, Germany, 2013. 
22. Minh, D.T.; The, L.T.; Bao, N.T. Performance of $\mathrm{Al}_{2} \mathrm{O}_{3}$ nanofluids in minimum quantity lubrication in hard milling of 60Si2Mn steel using cemented carbide tools. Adv. Mech. Eng. 2017, 9, 1-9. [CrossRef]

23. Long, T.T.; Duc, T.M. Micro/Nanofluids in Sustainable Machining. In Microfluidics and Nanofluidics; IntechOpen: London, UK, 2018.

24. Li, B.; Li, C.; Zhang, Y.; Wang, Y.; Jia, D.; Yang, M.; Zhang, N.; Wu, Q.; Han, Z.; Sun, K. Heat transfer performance of MQL grinding with different nanofluids for Ni-based alloys using vegetable oil. J. Clean. Prod. 2017, 154, 1-11. [CrossRef]

25. Lee, P.-H.; Nam, J.S.; Li, C.; Lee, S.W. An experimental study on micro-grinding process with nanofluid minimum quantity lubrication (MQL). Int. J. Precis. Eng. Manuf. 2012, 13, 331-338. [CrossRef]

26. Ali, M.K.A.; Hou, X.; Mai, L.; Cai, Q.; Turkson, R.F.; Chen, B. Improving the tribological characteristics of piston ring assembly in automotive engines using $\mathrm{Al}_{2} \mathrm{O}_{3}$ and $\mathrm{TiO}_{2}$ nanomaterials as nano-lubricant additives. Tribol. Int. 2016, 103, 540-554. [CrossRef]

27. Pashmforoush, F.; Bagherinia, R.D. Influence of water-based copper nanofluid on wheel loading and surface roughness during grinding of Inconel 738 superalloy. J. Clean. Prod. 2018, 178, 363-372. [CrossRef]

28. Uysal, A.; Demiren, F.; Altan, E. Applying Minimum Quantity Lubrication (MQL) Method on Milling of Martensitic Stainless Steel by Using Nano $\mathrm{MoS}_{2}$ Reinforced Vegetable Cutting Fluid. Procedia Soc. Behav. Sci. 2015, 195, 2742-2747. [CrossRef]

29. Zhang, Y.; Li, C.; Jia, D.; Li, B.; Wang, Y.; Yang, M.; Hou, Y.; Zhang, X. Experimental study on the effect of nanoparticle concentration on the lubricating property of nanofluids for MQL grinding of Ni-based alloy. $J$. Mater. Process. Technol. 2016, 232, 100-115. [CrossRef]

30. Yıldırım, Ç.V.; Sarıkaya, M.; Kıvak, T.; Şirin, Ş. The effect of addition of hBN nanoparticles to nanofluid-MQL on tool wear patterns, tool life, roughness and temperature in turning of Ni-based Inconel 625. Tribol. Int. 2019, 134, 443-456. [CrossRef]

31. Garg, A.; Sarma, S.; Panda, B.; Zhang, J.; Gao, L. Study of effect of nanofluid concentration on response characteristics of machining process for cleaner production. J. Clean. Prod. 2016, 135, 476-489. [CrossRef]

32. Lee, G.-J.; Park, J.-J.; Lee, M.-K.; Rhee, C.K. Stable dispersion of nanodiamonds in oil and their tribological properties as lubricant additives. Appl. Surf. Sci. 2017, 415, 24-27. [CrossRef]

33. Wang, Y.; Li, C.; Zhang, Y.; Li, B.; Yang, M.; Zhang, X.; Guo, S.; Liu, G. Experimental evaluation of the lubrication properties of the wheel/workpiece interface in MQL grinding with different nanofluids. Tribol. Int. 2016, 99, 198-210. [CrossRef]

34. Luo, T.; Wei, X.; Huang, X.; Huang, L.; Yang, F. Tribological properties of $\mathrm{Al}_{2} \mathrm{O}_{3}$ nanoparticles as lubricating oil additives. Ceram. Int. 2014, 40, 7143-7149. [CrossRef]

35. Pervaiz, S.; Deiab, I.; Rashid, A.; Nicolescu, M. Minimal quantity cooling lubrication in turning of Ti6Al4V: Influence on surface roughness, cutting force and tool wear. Proc. Inst. Mech. Eng. Part B J. Eng. Manuf. 2017, 231, 1542-1558. [CrossRef]

36. Maruda, R.W.; Krolczyk, G.M.; Feldshtein, E.; Nieslony, P.; Tyliszczak, B.; Pusavec, F. Tool wear characterizations in finish turning of AISI 1045 carbon steel for MQCL conditions. Wear 2017, 372, 54-67. [CrossRef]

37. Maruda, R.W.; Krolczyk, G.M.; Feldshtein, E.; Pusavec, F.; Szydlowski, M.; Legutko, S.; Sobczak-Kupiec, A. A study on droplets sizes, their distribution and heat exchange for minimum quantity cooling lubrication (MQCL). Int. J. Mach. Tools Manuf. 2016, 100, 81-92. [CrossRef]

38. Maruda, R.W.; Krolczyk, G.M.; Wojciechowski, S.; Zak, K.; Habrat, W.; Nieslony, P. Effects of extreme pressure and anti-wear additives on surface topography and tool wear during MQCL turning of AISI 1045 steel. J. Mech. Sci. Technol. 2018, 32, 1585-1591. [CrossRef]

39. Maruda, R.; Krolczyk, G.; Niesłony, P.; Krolczyk, J.; Legutko, S.; Krolczyk, G. Chip Formation Zone Analysis During the Turning of Austenitic Stainless Steel 316L under MQCL Cooling Condition. Procedia Eng. 2016, 149, 297-304. [CrossRef]

40. Krolczyk, G.; Maruda, R.; Krolczyk, J.; Nieslony, P.; Wojciechowski, S.; Legutko, S. Parametric and nonparametric description of the surface topography in the dry and MQCL cutting conditions. Measurement 2018, 121, 225-239. [CrossRef]

41. Maruda, R.W.; Feldshtein, E.; Legutko, S.; Krolczyk, G.M. Research on emulsion mist generation in the conditions of minimum quantity cooling lubrication (MQCL). Teh. Vjesn. Tech. Gaz. 2015, 22, 1213-1218. 
42. Gutnichenko, O.; Bushlya, V.; Bihagen, S.; Ståhl, J.-E. Influence of graphite nanoadditives to vegetable-based oil on machining performance when MQCL assisted hard turning. Procedia CIRP 2018, 77, 437-440. [CrossRef]

43. Sartori, S.; Ghiotti, A.; Bruschi, S. Temperature effects on the Ti6Al4V machinability using cooled gaseous nitrogen in semi-finishing turning. J. Manuf. Process. 2017, 30, 187-194. [CrossRef]

44. Sartori, S.; Ghiotti, A.; Bruschi, S. Solid Lubricant-assisted Minimum Quantity Lubrication and Cooling strategies to improve Ti6Al4V machinability in finishing turning. Tribol. Int. 2018, 118, 287-294. [CrossRef]

45. Busch, K.; Hochmuth, C.; Pause, B.; Stoll, A.; Wertheim, R. Investigation of Cooling and Lubrication Strategies for Machining High-temperature Alloys. Procedia CIRP 2016, 41, 835-840. [CrossRef]

46. Pereira, O.; Català, P.; Rodríguez, A.; Ostra, T.; Vivancos, J.; Rivero, A.; López-de-Lacalle, L.N. The Use of Hybrid $\mathrm{CO}_{2}+\mathrm{MQL}$ in Machining Operations. Procedia Eng. 2015, 132, 492-499. [CrossRef]

47. Bagherzadeh, A.; Budak, E. Investigation of machinability in turning of difficult-to-cut materials using a new cryogenic cooling approach. Tribol. Int. 2018, 119, 510-520. [CrossRef]

48. Iturbe, A.; Hormaetxe, E.; Garay, A.; Arrazola, P.J. Surface Integrity Analysis when Machining Inconel 718 with Conventional and Cryogenic Cooling. Procedia CIRP 2016, 45, 67-70. [CrossRef]

49. Uhlmann, E.; Bilz, M.; Mankiewicz, J.; Motschmann, S.; John, P. Machining of Hygroscopic Materials by High-pressure $\mathrm{CO}_{2}$ Jet Cutting. Procedia CIRP 2016, 48, 57-61. [CrossRef]

50. Jamil, M.; Khan, A.M.; Hegab, H.; Gong, L.; Mia, M.; Gupta, M.K.; He, N. Effects of hybrid $\mathrm{Al}_{2} \mathrm{O}_{3}-\mathrm{CNT}$ nanofluids and cryogenic cooling on machining of Ti-6Al-4V. Int. J. Adv. Manuf. Technol. 2019, 102, 3895-3909. [CrossRef]

51. Hilsch, R. The Use of the Expansion of Gases in a Centrifugal Field as Cooling Process. Rev. Sci. Instrum. 1947, 18, 108-113. [CrossRef]

52. Duc, T.M.; Long, T.T.; Chien, T.Q. Performance Evaluation of MQL Parameters Using $\mathrm{Al}_{2} \mathrm{O}_{3}$ and $\mathrm{MoS}_{2}$ Nanofluids in Hard Turning 90CrSi Steel. Lubricants 2019, 7, 40. [CrossRef]

53. Rahmati, B.; Sarhan, A.A.; Sayuti, M. Morphology of surface generated by end milling AL6061-T6 using molybdenum disulfide $\left(\mathrm{MoS}_{2}\right)$ nanolubrication in end milling machining. J. Clean. Prod. 2014, 66, 685-691. [CrossRef]

54. Hegab, H.; Kishawy, H.A.; Umer, U.; Mohany, A. A model for machining with nano-additives based minimum quantity lubrication. Int. J. Adv. Manuf. Technol. 2019, 102, 2013-2028. [CrossRef]

55. Hegab, H.; Kishawy, H.A. Towards Sustainable Machining of Inconel 718 Using Nano-Fluid Minimum Quantity Lubrication. J. Manuf. Mater. Process. 2018, 2, 50. [CrossRef]

56. Hegab, H.; Umer, U.; Soliman, M.; Kishawy, H.A. Effects of nano-cutting fluids on tool performance and chip morphology during machining Inconel 718. Int. J. Adv. Manuf. Technol. 2018, 96, 3449-3458. [CrossRef]

57. Duc, T.M.; Long, T.T.; Dong, P.Q.; Ngoc, T.B. Applied Research of Nanofluids in MQL to Improve Hard Milling Performance of $60 \mathrm{Si}_{2} \mathrm{Mn}$ Steel Using Carbide Tools. Am. J. Mech. Eng. 2017, 5, 228-233. 